\title{
Advance care planning in patients with brain tumours: A prospective cohort study
}

\author{
Krystal Song ${ }^{1, *}$, Bhasker Amatya ${ }^{1}$ and Fary Khan ${ }^{1}$ \\ 1 Department of Rehabilitation Medicine, Royal Melbourne Hospital, Royal Park Campus, 34-54 Poplar Road, Parkville, Victoria, Australia
}

\begin{abstract}
Objectives: To assess and understand the awareness and experience of brain tumour (BT) patients in discussing Advance Care Planning (ACP), to identify main symptoms experienced, physical and functional status perceived quality of life, and level of coping. Methods: A prospective cohort study with an initial open-ended questionnaire followed by semi-structured interview questions regarding ACP with 18 patients diagnosed with BT (WHO Grade I-IV, metastatic BT) in hospital and community. Standardized assessments measured coping strategies, and quality of life (QoL). Interview transcripts regarding ACP discussions were analyzed, coded and interpreted using qualitative analytic techniques for thematic analyses. Results: Participants' mean age was 51 years (range 22-65 years), female (61\%); median time since BT diagnosis was 1.5 years and just over half (56\%) had glioblastoma multiforme (GBM). Fatigue was the most common symptom reported by $83 \%$ of participants. Overall, participants indicated good QoL and used more problem-focused coping strategies including 'acceptance' and 'positive reframing'. Thematic analyses indicated that participants had limited awareness and understanding of ACP, variable views on appropriate timing of ACP discussions and change of decisions over illness trajectory. Most felt able to discuss ACP and preferred dedicated sessions by a trained health professional. Conclusion: This study highlights the importance of providing timely information regarding ACP to BT patients during the course of their disease. Established ACP discussions have an important role in enhancing patient autonomy and to guide delivery of end-of-life care. The demonstrated low uptake of ACP in this pilot study shows need for improved awareness in clinical practice for timely ACP discussions and multifaceted interventions system-wide in implementing ACP.
\end{abstract}

Keywords: advance care planning; brain cancer; brain tumour; glioblastoma; qualitative research

\section{Introduction}

Primary brain tumours (BT) are a diverse group of neoplasms, affecting approximately seven persons per 100,000 population annually, worldwide [1]. In Australia, there are more than 1200 deaths from malignant and benign BT annually. Approximately 50\% of primary BT are gliomas and half of these are glioblastoma multiforme (GBM) [1, 2], which are aggressive and fatal. The five year survival rates in both groups are $1.9 \%$ and $9.8 \%$ respectively $[3,4]$. Frequently cited negative features of the disease include the lack of curable treatments and/ or physical problems, but also the rapidity of intellectual and cognitive decline [5]. BT also causes other disabilities such as fatigue, difficulties with mobility and self-care, behavioral dysfunction, psychological problems, social and vocational issues. It often disrupts family life, work and recreation, with implications for caregivers, health and social services. Caregiver strain can involve role reversal within family, physical and financial strain, and reduced quality of life (QoL) [6].

Due to high mortality rates and unpredictable disease trajectories, earlier discussions regarding Advance Care Planning (ACP) are highly relevant in this population. The Australian Guidelines - A National Framework for Advance Care Directives (developed in 2011) [7] offers a standardized approach for key ethical, best practice standards and practical aspects of Advance Care Directives (ACD). These documents can be completed by people in any setting and records personal values, preferred health outcomes, goals of care, and appointed substitute decisionmaker or combination of these (refer to Appendix A). ACP is therefore a process, which involves decisions made by patients, in consultation with surrogate decision-makers, family, and health care providers regarding their future health care wishes should they later become incapable of expressing such preferences [8]. ACP is recommended as routine part of care [9] and highlights the importance of clinicians and patients in sharing a common understanding of the patients' illness, prognosis and preferences.

*Corresponding author: Dr. Krystal Song, Department of Rehabilitation Medicine, Royal Melbourne Hospital, Royal Park Campus, 34-54 Poplar Road, Parkville, Victoria, Australia, Tel.: 613 83872000; Fax: 61383872222 Email: krystal.song@mh.org.au

Received 21 May 2015 Revised 13 July 2015 Accepted 22 July 2015 Published 29 July 2015

Citation: Song K, Amatya B, Khan F. Advance care planning in patients with brain tumours: A prospective cohort study. J Cancer Res Ther. 2015; 3(7):8591. DOI:10.14312/2052-4994.2015-12

Copyright: (C) 2015 Song K, et al. Published by NobleResearch Publishers. This is an open-access article distributed under the terms of the Creative Commons Attribution License, which permits unrestricted use, distribution and reproduction in any medium, provided the original author and source are credited. 
Although ACP is recognized as integral to quality cancer care, it remains poorly integrated in routine care. Common issues that may arise as a result of lack of ACP discussions include potential mismatch between doctors and family's perception of patients' actual preferences with respect to life sustaining interventions. There may be overestimation of prognosis, or success of aggressive interventions like cardiopulmonary resuscitation (CPR), and lack of understanding of the role of such interventions in the context of advanced cancer by patients and families [10]. Cultural, spiritual or religious factors also impact on establishing ACP [10].

For cancer patients, ACP is a very individualized and dynamic process which involves the "actualization, relinquishing and rejecting" of its individual components [10]. One study reported that common end-of-life (EOL) decisions in BT were tube feeding (13\%), hydration (87\%), steroid interruption (45\%) and palliative sedation (13\%), with only $5 \%$ having established ACD about EOL treatment [11]. Other studies report that $10-45 \%$ of high grade glioma patients had ACDs during their last three months before death [12]. Progressive neurological deficits and loss of consciousness often meant that some of these decisions had to be made on their behalf. Reactions can change over time, and studies show that routinely and sensitively discussing ACP with cancer patients (including BT) at various time points over a series of conversations, rather than a single event, across their disease trajectory is valuable [10].

There is limited data for provision of ACP discussions in BT patients with complex neuropalliative care needs. A prospective cohort study using qualitative and quantitative methods explored patient experience with ACP and their understanding to improve current practices and processes for clear communication with regards to their wishes. In addition, factors impacting decision-making were explored.

\section{Materials and methods}

\section{Participants and setting}

This study was approved by the Human Research and Ethics Committee (HREC) of the Royal Melbourne Hospital (RMH), a tertiary facility in Victoria, Australia (HREC 2014.221). Participants were recruited from the neurosurgery database from February 2015 to April 2015. A total of 19 patients were identified as eligible, however, 1 patient declined to participate due to personal reasons. Hence, 18 consecutive patients were prospectively recruited following completion of treatment including surgery, chemotherapy or radiotherapy. Patients recruited had a diagnosis of BT (ranging from WHO Grade I-IV or metastatic BT), in the hospital and community settings, and were at different stages of illness course including the EOL with varying levels of physical and functional needs.

Inclusion criteria included persons with BT aged 18 years and above, with confirmed diagnosis of WHO Grade I-IV BT or metastatic BT types, made by relevant specialists, residing in Victoria, able and willing to give informed consent, medically stable, without severe cognitive impairment (MMSE $\geq 22$ ) and live within a feasible distance (60 km radius) for home interviews. Exclusion criteria were those with severe cognitive impairment (MMSE < 22) and those who could not adequately communicate in English.

\section{Procedure}

An invitation letter was mailed to all potentially eligible. Those who responded were contacted by phone for study rationale and objectives. Once informed consent was obtained, the participant was recruited by the primary researcher. Participants were aware that they could withdraw from the study at any time without having reason for doing so.

The primary researcher conducted ACP discussions and measurements utilizing face-to-face interviews. Participants were interviewed at a venue of their choice (home/ hospital), and if they were an inpatient, interviews were performed at a time most convenient for them in a private ward office. Each interview took approximately 1.5 hours. Participants were given rest breaks and assistance (if required) to complete the questionnaires, but were not prompted.

All interviews were audiotaped, transcribed, anonymously labelled with study code by the primary researcher and information was stored in a locked office at the RMH. Information was entered into a password protected database once all information had been collected. Study patient numbers were determined when data saturation point was reached; this describes a point beyond which no new concepts arose as a result of further interviews [13].

\section{Measurement \& questionnaires}

Each participant was interviewed using a structured format wherever possible. Socio-demographic data and medical history were obtained from medical records or from participants.

Participants' main symptoms experienced in the context of BT that were most significant were recorded. These symptoms included: drowsiness, weakness, seizures, memory loss, dysphagia, nausea, vomiting, pain, headache, or fatigue as examples. Similarly, their mobility and activities of daily living (ADLs) functional status were noted.

Two questionnaires examined participants' perceived QoL and coping. The McGill Quality of Life (MQOL) [14] is a valid and reliable 16-item questionnaire with each question rated from 0 (not at all) to 10 (extremely). It has also been previously used in ACP studies [15]. The MQOL five domains include: 2 health related (physical wellbeing, physical symptoms) and 3 non-health related (existential wellbeing, psychological symptoms and support). For each domain, the score is the mean of values of the relative items. A total rate is obtained as the mean value of the score of the five domains. In addition, the participant was asked to indicate his/her perceived QoL in the past two days in a single item scale (MQOL-SIS), rated from 0 (very bad) to 10 (excellent). Concepts within the MQOL overlap with elements of the $A C P$, however the ACP discussions add patients' views and preferences with regards to treatment options. 
The Brief COPE inventory [16] has 14 subscales including active coping, planning, positive reframing, acceptance, humour, religion, using emotional support, using instrumental support, self-distraction, denial, venting, substance use, behavioural disengagement and selfblame. Each subscale has 2 items. This inventory provides a brief measure that assesses several responses known to be relevant to effective and ineffective coping.

After rapport had been established with the participant, participants were then interviewed about ACP using initial open-ended questions followed by semi-structured preformatted interview questions (refer to Appendix B), to aid fluency of discussions. This was made flexible to follow new lines that evolved during the discussion. Patients were also informed of the option to be referred for supportive counselling should they experience any significant distress.

\section{Data analysis}

A series of descriptive analyses were conducted on patient demographics and disease characteristics data. Additional analyses were conducted on the subscale scores of the MQOL, Brief COPE, and presented in a descriptive manner. Statistical Package for Social Sciences (SPSS), v. 18.0 (SPSS Inc, Chicago, IL) was used for all analyses.

Interview transcripts regarding ACP discussions with the participants were analyzed, coded and interpreted using thematic analysis, guided by the analytic hierarchy [17]. Thematic analysis was based on an inductive process that allowed for themes to emerge, and to enable management of large amounts of qualitative data in a credible and robust manner [18]. Transcripts were individually read, 'open' coded, and then emergent thematic features were collectively discussed, categorized and summarized under each topic domain by 2 investigators (KS, FK). This summary was then further summarized and certain points re-categorized as appropriate until agreement was reached. When no new themes were found, saturation was considered to be achieved.

\section{Results}

\section{Sample characteristics}

The socio-demographic and clinical characteristics of study participants $(n=18)$ are presented in Table 1 . The mean age of the participants was 51 years (range 22-65 years), majority were female $(n=11,61 \%)$ and Caucasian (57\%). Median time since BT diagnosis was 1.5 years [InterQuartile Range (IQR), 0.2 to 3.4 years]. Just over half (56\%) had GBM and 2 participants had metastatic BT. All except one had surgery, and $83 \%$ had radiotherapy. Patients were at different stages across the illness trajectory at time of interview; three had completed active treatment including chemotherapy or radiotherapy, 9 had plateaued, and 6 had recent cranial surgery.

\section{Current symptoms}

Fatigue was the most common symptom reported by the participants $(83 \%)$, followed by pain/headache $(50 \%)$, a quarter reported cognitive impairment $(n=5,28 \%)$, and 4 visual impairment (diplopia). Two-thirds of the sample
Table 1 Socio-demographic and clinical characteristics of participantst $(n=18)$.

\begin{tabular}{|c|c|}
\hline Characteristics & $\begin{array}{c}n,(\%) \\
\text { (unless stated different) }\end{array}$ \\
\hline Age (mean $\pm S D$ (range) years & $50.9 \pm 11.9(22-65)$ \\
\hline Sex - Female & $11(61.1)$ \\
\hline Marital status - Married/ Partner & $15(83.3)$ \\
\hline Living arrangements - Family & $17(94.4)$ \\
\hline \multicolumn{2}{|l|}{ Education } \\
\hline Secondary & $8(44.4)$ \\
\hline Tertiary/ Postgraduate & $10(55.6)$ \\
\hline Ethnicity - Caucasian & $12(66.7)$ \\
\hline \multicolumn{2}{|l|}{ Religion } \\
\hline Christian & $2(11.1)$ \\
\hline Other & $15(83.3)$ \\
\hline \multicolumn{2}{|l|}{ Brain tumour type } \\
\hline Meningioma & $6(33.3)$ \\
\hline GBM & $10(55.6)$ \\
\hline Metastatic & $2(11.1)$ \\
\hline Time since diagnosis (Median, IQR) years & $1.5(0.2,3.4)$ \\
\hline Setting - Outpatient & $13(72.2)$ \\
\hline \multicolumn{2}{|l|}{ Treatments } \\
\hline Chemotherapy & $11(61.1)$ \\
\hline Radiotherapy & $15(83.3)$ \\
\hline Surgery & $17(94.4)$ \\
\hline \multicolumn{2}{|l|}{ Comorbidities } \\
\hline Diabetes & $1(5.6)$ \\
\hline Hypertension & $1(5.6)$ \\
\hline Hypercholesterolemia & $1(5.6)$ \\
\hline Depression & $5(27.8)$ \\
\hline Anxiety & $7(38.9)$ \\
\hline Other (gout, arthritis, asthma) & $3(16.7)$ \\
\hline \multicolumn{2}{|l|}{ Main symptoms } \\
\hline Fatigue & $15(83.3)$ \\
\hline Headache/pain & $9(50.0)$ \\
\hline Cognitive impairment & $5(27.8)$ \\
\hline Visual impairment (diplopia) & $4(22.2)$ \\
\hline Seizures & $2(11.1)$ \\
\hline Dysphasia & $3(16.7)$ \\
\hline Assistance required for mobility & $7(38.9)$ \\
\hline Assistance required for ADLs & $13(72.2)$ \\
\hline
\end{tabular}

Abbreviations: ADLs = activities of daily living; GBM: glioblastoma; IQR= Inter quartile range: $\mathrm{SD}=$ standard deviation

$(n=13,72 \%)$ required assistance for ADLs and 7 participants (39\%) assistance for mobility. Just over one-third of all participants reported anxiety (39\%), while depression was reported by 5 participants (28\%). All participants' cognition appeared grossly intact during the interviews, with MMSE scores ranging from 27-30. 


\section{Quality of life, and coping strategies}

Overall, participants indicated good QoL (MQOL total mean: 99 \pm 13 , SIS mean 6.7 \pm 1.8 ). The lowest mean scores (indicating greatest distress) in the MQOL for participants were on subscales for 'physical symptoms' (mean $=14.4 \pm 3.1$, range $=6-20)$, 'existential well-being' (mean $=39.7 \pm 8.7)$ and psychological well-being' (mean $=$ $29.8 \pm 8.2$ ). Problem-focused coping strategies were more commonly used than emotion-focused coping strategies (Brief COPE). Acceptance, active coping, using emotional support and positive reframing were the most commonly used problem-focused strategies by participants in the study (Table 2). Amongst the emotion-focused coping strategies, 'self-distraction' was the most commonly used strategy by the participants (Table 2).

Table 2 Descriptive statistics for subscales of the of McGill Quality of Life (MQOL), and Brief COPE $(n=18)$.

\begin{tabular}{|c|c|c|}
\hline Measurement scales & Mean (SD) & Range \\
\hline \multicolumn{3}{|l|}{$M Q O L$} \\
\hline Total & $99.0(13.0)$ & $0-130$ \\
\hline Single item scale (SIS) & $6.7(1.8)$ & $0-10$ \\
\hline Physical symptoms & $14.4(3.1)$ & $0-30$ \\
\hline Physical well-being & $7.2(2.2)$ & $0-10$ \\
\hline Psychological symptoms & $29.8(8.2)$ & $0-40$ \\
\hline Existential wellbeing & $39.7(8.7)$ & $0-60$ \\
\hline Support & $15.2(3.9)$ & $0-20$ \\
\hline \multicolumn{3}{|l|}{$\begin{array}{l}\text { Brief COPE } \\
\text { Problem focus coping strategies }\end{array}$} \\
\hline Active coping & $6.2(2.0)$ & $2-8$ \\
\hline Planning & $5.7(2.2)$ & $2-8$ \\
\hline Positive reframing & $5.9(2.2)$ & $2-8$ \\
\hline Acceptance & $6.8(1.7)$ & $2-8$ \\
\hline Humour & $5.2(2.6)$ & $2-8$ \\
\hline Religion & $3.6(2.2)$ & $2-8$ \\
\hline Using emotional support & $6.7(2.0)$ & $2-8$ \\
\hline Using instrumental support & $5.7(2.1)$ & $2-8$ \\
\hline \multicolumn{3}{|l|}{ Emotion-focused coping strategies } \\
\hline Self-distraction & $5.7(1.8)$ & $2-8$ \\
\hline Denial & $2.9(1.6)$ & $2-8$ \\
\hline Venting & $3.8(2.1)$ & $2-8$ \\
\hline Substance use & $2.0(0.0)$ & $2-8$ \\
\hline Behavioural disengagement & $2.7(1.2)$ & $2-8$ \\
\hline Self-blame & $2.4(0.8)$ & $2-8$ \\
\hline
\end{tabular}

\section{Themes surrounding ACP discussions}

\section{Box 1: Quality of life is very important}

The interviews highlighted that QoL rather than quantity was a premium to BT participants. Participants emphasized the importance of mental functioning and physical ability in their definitions of QoL. This draws to the unique experiences of BT patients.

\begin{tabular}{|c|c|}
\hline Categories & \\
\hline \multirow[t]{3}{*}{$\begin{array}{l}\text { QoL of life } \\
\text { versus quantity }\end{array}$} & $\begin{array}{l}\text { "I would not want to be hooked up to machines, CPR, } \\
\text { intubation or without general quality of life..." }\end{array}$ \\
\hline & $\begin{array}{l}\text { "I certainly don't want to be kept alive just for the } \\
\text { sake of it... you have got to have some quality of life, } \\
\text { you can't just lie in bed... Quality of life for me ... is to } \\
\text { be able to get out of bed at least..." }\end{array}$ \\
\hline & $\begin{array}{l}\text { "I think I would be rational about it, it depends on } \\
\text { whether the brain tumour affected my cognitive } \\
\text { reasoning, it's hard to know and make decisions..." }\end{array}$ \\
\hline
\end{tabular}

Box 2: The lack of awareness, understanding, information and documentation regarding $A C P$

Almost all participants had limited awareness of ACP. Exploration of participants' understanding about ACP indicated vague or no direct knowledge. Three $(n=3)$ participants reported awareness of ACP, however only 2 demonstrated an understanding of ACP. Only 1 of these 3 patients had initiated formal ACP discussions with palliative care services. Many also reported lack of information being provided about the ACP process. None of the participants reported having read an ACP information brochure or pamphlet.

With regards to ACP documentation, 6 participants had nominated a Medical Enduring Power of Attorney (MEPOA). None had documented in a Statement of Choices form, ACD or Refusal of Treatment certificate. All participants were unaware of the variety of ways of formal documentation for ACP, although 6 participants had nominated a MEPOA. Three $(n=3)$ out of all participants were linked into palliative care services.

\begin{tabular}{ll}
\hline Categories & \\
\hline Lack of awareness & "what you are talking about now is the first \\
& time I've heard of it.. I never heard of it until \\
& you brought it up..." \\
& "I know of it but I don't know the details..." \\
& "that prior to discharge, you have what \\
& you need discussed... for example, coming \\
& home and having someone to help me with \\
& housework, or if there was someone at home \\
& to help me..." \\
& "that you are looking from all aspects, not just \\
& relating to health. Looking after everything... \\
& take person as a whole and you look at every \\
& aspect of life - physically, emotionally and in \\
& future as well, what will happen, what's going \\
& on... I mean discharge planning..." \\
& "I've been given so much stuff. We came back \\
& with several booklets... I don't know about \\
& advance care planning..." \\
& "I'm linked in with palliative care but have no \\
& information regarding advance care planning" \\
& "I haven't really thought about it, you are the \\
& first person who has talked about this... I need \\
& to research more about it." \\
\hline Lack of information &
\end{tabular}

Box 3: Timing of ACP discussions and change of ACP decisions over illness trajectory

Most participants had variable views on when ACP discussions should take place. Most did not want to hear about it during time of diagnosis and only when they have come to terms with the diagnosis, or gone through initial 
stages of surgery and anticancer therapy. This was related to uncertainty of individual disease course and lack of individualized information regarding prognosis, impacting on timing of these discussions.

Most participants had uncertain views on whether they would change their decisions made in relation to ACP over time. This study indicated that participants' preferences for life prolonging treatments and goals of care would change depending on how ill they were. Seven participants $(n=7)$ stated that they would not change their decisions during their disease course.

\begin{tabular}{ll}
\hline Categories & \\
\hline Views on timing of & "Not on the day of diagnosis... I think a few \\
discussions & weeks after would be better, in a private \\
& setting, after radiotherapy, with a month or \\
& two off. You have a lot of time to process \\
& what's going on, the severity but over the \\
& initial shock of diagnosis..." \\
& "I would probably prefer before you came \\
& end stage, because you are more yourself \\
& and not feeling very sick...I think everyone \\
& is going to be different as I'm a lot more \\
& positive than most people are. I think for \\
& some people, this would be a bit more \\
& confronting..." \\
& "it can be discussed at any time, but for me, \\
& I think I'm still well and good to talk about it \\
& now and well enough to make a decision..." \\
& "maybe after my MRI... knowing what \\
& details and treatment options I have.." \\
"I don't know... I know at the moment, my & tumour is reducing so I'm doing well. But \\
if another MRI shows up a recurrence, \\
then I would have another conversation. \\
So probably, I haven't really made up my \\
mind..." \\
"probably not.. I wouldn't change my \\
mind..." \\
Change of decisions in to ACP over time
\end{tabular}

\section{Box 4: Who they felt most comfortable talking to about ACP}

Twelve $(n=12)$ out of 18 participants felt that they would be most comfortable talking to their family regarding ACP. Five $(n=5)$ felt most comfortable talking to their specialist and $1(n=1)$ felt unsure.

Of whom participants felt appropriate as mediators for ACP discussions, $3(n=3)$ felt that the social worker would be preferable, $9(n=9)$ preferred a medical facilitator and $6(n=6)$ either a medical or non-medical facilitator. In this study, most reported that they would prefer to have verbal conversations, with initial prompting in discussing ACP.

\begin{tabular}{ll}
\hline Categories & \\
\hline ACP mediator & "I would suggest that if the social worker had \\
& enough knowledge about ACP, then he/she would \\
& be the best person. Because doctors and surgeons \\
& are too busy, but if not, then the one who is most \\
& knowledgable. It's got be tailored to you." \\
& "medical facilitator as long as there is a holistic \\
& approach to ACP"
\end{tabular}

\section{Box 5: Future healthcare decisions}

Only a small number of patients $(n=5)$ had talked with family members regarding future preferred health care outcomes. Three $(n=3)$ out of all participants had discussed their preferred resuscitation status with their health care professional. Most participants had not spoken in depth with their doctors about the future or decisions relating to preferred health outcomes if there was a potential deterioration in health. Most felt that there was not enough time during clinic appointments for these discussions to occur. Most also felt that it was difficult to make decisions without adequate knowledge of their likely individual prognosis, and future healthcare choices.

Nine $(n=9)$ patients expressed that they would trust their health professionals in making future health care decisions in their best interests. However, they would like these decisions considered in conjunction with their family members.

\begin{tabular}{ll}
\hline Categories & \\
\hline $\begin{array}{l}\text { Lack of ACP discussions with } \\
\text { health care professionals }\end{array}$ & $\begin{array}{l}\text { "no, you don't have time when you } \\
\text { are in and out, they are so busy.. } \\
\text { I have not talked to my GP either } \\
\text { and I don't have a lot of time with } \\
\text { her as well..." } \\
\text { "no, they are just waiting for tests } \\
\text { before making decisions before } \\
\text { MRI, they are trying not to scare } \\
\text { you too much.." } \\
\text { "as long as my son and daughter } \\
\text { are there, they can make a } \\
\text { making decisions regarding life- } \\
\text { prolonging treatments } \\
\text { outcomes.." } \\
\text { "No, I don't want that... that would } \\
\text { be tantamount to me being kept } \\
\text { alive for no reason as their duty is } \\
\text { to keep me alive..." } \\
\text { "I've got no real problem with that, } \\
\text { provided that you trust them and } \\
\text { would have my best interests..." }\end{array}$ \\
\hline
\end{tabular}

Box 6: Potential barriers, challenges and suggestions for discussing $A C P$

Fifteen $(n=15)$ participants in the study felt that there were no concerns in completing an ACP. Only 2 participants felt not ready in completing an ACP, however all felt able to discuss the topic.

Potential strategies of improving the communication of ACP with patients included being provided possible disease course, options for treatments and their effects that are needed to do ACP. Most indicated that ACP information provision could be provided in the form of written or verbal information, however almost all participants in this study preferred verbal format. They also did not prefer to be overwhelmed by too much reading material.

Some felt that there was limited availability of dedicated sessions to specifically discuss and bring up the topic, including the availability of trained staff with time. Most reported that the ACP discussion was worthwhile having, and the information valuable. Many would like further information regarding where they could access this information online and the process of documentation of their goals of care. 


\begin{tabular}{|c|c|}
\hline Categories & \\
\hline \multirow[t]{3}{*}{$\begin{array}{l}\text { Perceived challenges } \\
\text { in discussing ACP }\end{array}$} & $\begin{array}{l}\text { "I don't feel so ready that I'm up for an } \\
\text { advance care plan when I'm hoping to } \\
\text { improve... I don't really want to talk about } \\
\text { something that may not happen.." }\end{array}$ \\
\hline & $\begin{array}{l}\text { "only that it might be locked into just because I } \\
\text { feel this way now..." }\end{array}$ \\
\hline & "I think I'm too young to think about it..." \\
\hline \multirow[t]{3}{*}{$\begin{array}{l}\text { Suggested } \\
\text { improvements for ACP } \\
\text { discussions }\end{array}$} & $\begin{array}{l}\text { "I think it depends on the person and age on } \\
\text { how to improve the process... People a lot } \\
\text { younger find electronic communication a lot } \\
\text { easier. I'm a chatty person, so verbal then } \\
\text { written information would be good. I think you } \\
\text { need to be prompted for these discussions." }\end{array}$ \\
\hline & $\begin{array}{l}\text { "for me, a lot of people like written, but I } \\
\text { prefer verbal - I listen.." }\end{array}$ \\
\hline & $\begin{array}{l}\text { "probably to go through it in a bit more detail, } \\
\text { in steps..." }\end{array}$ \\
\hline
\end{tabular}

\section{Discussion}

The findings from this pilot prospective cohort study demonstrate that BT patients experience complex neuropalliative needs and have limited awareness and discussions in relation to ACP. The participants in this study are similar to those in other studies demonstrating poor overall awareness of ACP [10, 18-20]. This issue highlights ongoing significant gaps in information provision, service delivery and clinical implications considering widespread national EOL initiatives that promote ACP. Key national initiatives like The Australian Evaluation and Quality Improvement Program (EQuIP) [21] seek to address this gap. EQuIP outlines critical standards for health care systems, including implementation of EOL policy and procedures, as well as support systems for patients and carers in documenting clear ACDs and goals of EOL. As part of organizational commitment to improve standards of care, steering committees in major tertiary hospitals have implemented quality programs including competency training in ACP, use of prompts and checklists, auditing systems and consumer education, with systems to formally evaluate effects of clinical documentation, clinical processes and outcomes related to ACP discussions. ACP is increasingly being adopted as part of standard routine care for patients across different stages of illness trajectory, with an emphasis on goals of care, along with preferences on future treatment options.

An important element is to promote awareness of ACP to all relevant teams involved in patient care in being proactive in EOL and ACP discussions. The specialist teams involved in delivery of care to BT patients include specialist neurosurgery, neuro-oncology, rehabilitation, and palliative care who provide diagnosis, surgery, anticancer therapy, shared clinical meetings, symptom management protocols, provision of equipment, social/psychological support, coordinated multidisciplinary team interventions, and terminal care support [22]. The growing uptake of the coined term 'neuro-rehab-palliative rehabilitation' [23] highlights the coordination and integration between these teams, whose care approaches often overlap, to deliver information regarding ACP to BT patients and provide support in patients' decision making. Studies have shown a higher satisfaction rate with overall care in the hospital, as patients are involved in active self-management of their care during their disease course, with the aim of enhancing QoL [8].

Although most participants in this study found ACP acceptable to discuss, which is consistent with other previous qualitative studies [24, 25], most participants in this study had variable views on when the implementation of the ACP process should occur. Illness uncertainty sometimes justified its delay or BT patients' perceived good health and treatment progress. Some studies indicated that discussions should not be initiated too early, but initiated before individuals became acutely unwell, and reviewed over multiple occasions [10]. This aspect is particularly important as patients' perspectives change over time, and are highly relevant in patients with malignant $\mathrm{BT}$, including GBM which often has a dire prognosis. The rapidity of cognitive decline and affected decision-making capacity in this population pertaining to future treatment preferences may influence their ability to participate in ACP during the later stages of disease process.

This study found only a small number of patients who had discussed their preferred health care outcomes with family or a health care professional. The fact that many participants felt comfortable talking to their family regarding ACP and welcomed such discussions is encouraging, as not only do patients reflect on their own treatment preferences, but families who are often experiencing carer burden had less traumatic stress, depression, anxiety and quality of patient death surrounding the time of patients' deaths [8].

One of the barriers in ACP discussions also included limited availability of dedicated sessions in discussing ACP. Studies highlighted that having sufficient time to talk through issues was very important when discussing ACP [19]. Patients tend to expect health professionals to initiate discussions and the use of non-medical ACP mediators including allied health and nursing, working in conjunction with doctors, can offer more availability of ACP to discuss realistic and achievable goals of care verbally, with tailored discussions. Other methods of providing proactive ACP information include brochures, pamphlets, patient education sessions and staff education workshops.

The limitations of this study include some bias as some BT patients declined to participate. The small number of patients in total in this study and at variety of stages across the illness trajectory would have impacted upon generalizability of findings. Despite this, there was a common view expressed by most patients and a variety of perspectives reported. The interview population was also restricted to those speaking English for pragmatic reasons such as funding resources for translators. This limits the generalizability of findings to other broader cultural groups. Furthermore, since we designed the interview guideline, there exists the possibility that the best questions were not asked and that particular avenues were not explored.

With current limited evidence on ACP in BT patients in Australia, and despite methodological limitations, this pilot study sheds light on this vulnerable cohort of patients, and their perspectives on ACP. It also adds to the accumulating evidence supporting ACP to become part of 
routine care, to ensure clinical interventions are not futile and inappropriate and encourages the ongoing efforts by hospital systems and processes to improve communication among treatment teams with patients. Future studies can extend results of this study and further improve service delivery and provide a coordinated, systematic model of patient centered Advance Care Planning.

\section{Conflict of interest}

The authors declare that they have no conflict of interest.

\section{Acknowledgements}

We would like to thank all participants in the study.

\section{Appendix A and B. Supplementary information}

Supplementary data associated with this article can be found in the online version at http://dx.doi. org/10.14312/2052-4994.2015-12.

\section{References}

[1] Flowers A. Brain tumors in the older person. Cancer Control. 2000; 7(6):523-538.

[2] Polednak AP, Flannery JT. Brain, other central nervous system and eye cancer. Cancer. 1995; 75(1 Suppl):330-337.

[3] Stupp R, Mason WP, van den Bent MJ, Weller M, Fisher B, et al. Radiotherapy plus concomitant and adjuvant temozolomide for glioblastoma. N Engl J Med. 2005; 352(10):987-996.

[4] Stupp R, Hegi ME, Mason WP, van den Bent MJ, Taphoorn MJ, et al. Effects of radiotherapy with concomitant and adjuvant temozolomide versus radiotherapy alone on survival in glioblastoma in a randomized phase III study: 5-year analysis of the EORTC-NCIC trial. Lancet Oncol. 2009; 10(5):459-466.

[5] Lipsman N, Skanda A, Kimmelman J, Bernstein M. The attitudes of brain cancer patients and their caregivers towards death and dying: a qualitative study. BMC Palliat Care. 2007; 6:7.

[6] Ness KK, Morris EB, Nolan VG, Howell CR, Gilchrist LS, et al. Physical performance limitations among adult survivors of childhood brain tumours. Cancer. 2010; 116 (12): 3034-3044.

[7] A National Framework for Advance Care Directives (September 2011). The clinical, technical and ethical principal committee of the Australian Health Minsters' Advisory Council. Accessed on 13 September 2014: www.ahmac.gov.au.

[8] Detering KM, Hancock AD, Reade MC, Silvester W. The impact of advance care planning on end of life care in elderly patients: randomised controlled trial. BMJ. 2010; 340:c1345.

[9] Clayton JM, Hancock KM, Butow PN, Tattersall MH, Currow DC, et al. Clinical practice guidelines for communicating prognosis and end of life issues with adults in the advanced stages of a life limiting illness and their caregivers. Med J Aust. 2007; 186(12 suppl):S77, S79, S83108.

[10] Michael N, O'Callaghan C, Clayton J, Pollard A, Stepanov N, et al. Understanding how cancer patients actualize, relinquish and reject advance care planning: implications for practice. Support Care Cancer. 2013; 21(8):2195-2205

[11] Pace A, Di Lorenzo C, Guariglia L, Jandolo B, Carapella CM, et al. End of life issues in brain tumour patients. J Neurooncol. 2009; 91(1):39-43.

[12] Koekkoek JA, Dirven L, Reijneveld JC, Sizoo EM, Pasman HR, et al. End of life care in high-grade glioma patients in three European countries: a comparative study. J Neurooncol. 2014; 120(2):303-310.

[13] Fins J, Maltby BS, Friedmann E, Greene MG, Norris K, et al. Contracts, covenants and advance care planning: an empirical study of the moral obligations of patient and proxy. J Pain Symptom Manage. 2005; 29(1):55-68.

[14] Cohen SR, Mount BM, Strobel MG, Bui F. The McGill Quality of Life Questionnaire: a measure of quality of life appropriate for people with advanced disease. A preliminary study of validity and acceptability. Palliat Med. 1995; 9(3):207-219.
[15] Wright AA, Zhang B, Ray A, Mack JW, Trice E, et al. Associations between end-of-life discussions, patient mental health, medical care near death and caregiver bereavement adjustment. JAMA. 2008; 300(14):16651673.

[16] Carver CS. You want to measure coping but your protocol's too long: consider the brief COPE. Int J Behav Med. 1997; 4(1):92-100.

[17] Spencer L, Ritchie J, O'Connor W. Analysis: Practices, Principles and Processes. In: Ritchie J, Lewis J, editors. Qualitative research practice. A guide for social science students and researchers. London: SAGE Publications, 2003. p. 199-218.

[18] Barnes K, Jones L, Tookman A, King M. Acceptability of an advance care planning interview schedhule: a focus group study. Palliat Med. 2007; 21(1):23-28.

[19] Cheang F, Finnegan T, Stewart C, Hession A, Clayton JM. Single-centre cross-sectional analysis of advance care planning among elderly patients. Intern Med J. 2014; 44(10):967-974.

[20] True G, Phipps EJ, Braitman LE, Harralson T, Harris D, et al. Treatment preferences and advance care planning at end of life: the role of ethnicity and spiritual coping in cancer patients. Ann Behav Med. 2005; 30(2):174-179.

[21] Australian Commission on Safety \& Quality in Health Care. National Safety \& Quality Health Service Standards, September 2011. ACSQHC, Sydney. Accessed on 13 September 2014: http://www.safetyandquality. gov.au/wp-content/uploads/2011/01/NSQHS-Standards-Sept2011.pdf

[22] Lin E, Rosenthal MA, Le BH, Eastman P. Neuro-oncology and palliative care: a challenging interface. Neuro Oncol. 2012; 14(Suppl 4):iv3-7.

[23] Turner-Stokes L, Sykes N, Silber E, Khatri A, Sutton L, et al. From diagnosis to death: Exploring the interface between neurology, rehabilitation and palliative care, in the management of people with long term neurological conditions. Clin Med. 2007; 7(2):129-136.

[24] Chapple A, Ziebland S, McPherson A. Stigma, shame and blame experienced by patients with lung cancer: qualitative study. BMJ. 2004; 328(7454):1470.

[25] Collins A, Lethborg C, Brand C, Gold M, Moore G, et al. The challenges and suffering of caring for people with primary malignant glioma: qualitative perspectives on improving current supportive and palliative care practices. BMJ Support Palliat Care. 2014; 4(1):68-76.

[26] Respecting Patient Choices. Accessed on 13 September 2014: http:// www.respectingpatientchoices.org.au 